\title{
Stabilometric response during single-leg stance after lower limb muscle fatigue
}

\author{
Carlos A. V. Bruniera ${ }^{1}$, Fernando R. P. G. Rogérioº ${ }^{2}$ André L. F. Rodacki $^{3}$
}

\begin{abstract}
Objective: This study sought to analyze the effect of muscle fatigue induced by active isotonic resistance training at a moderate intensity by measuring the knee extension motion during the stabilometric response in a single-leg stance among healthy university students who perform resistance training on a regular basis. Method: Eleven healthy university students were subjected to a one-repetition maximum (1RM) test. In addition, stabilometric assessment was performed before and after the intervention and consisted of a muscle fatiguing protocol, in which knee extension was selected as the fatiguing task. The Shapiro-Wilk test was used to investigate the normality of the data, and the Wilcoxon test was used to compare the stabilometric parameters before and after induction of muscle fatigue, at a significance level of $\mathrm{p} \leq 0.05$. Descriptive statistics were used in the analysis of the volunteers' age, height, body mass, and body mass index (BMI). Results: The sample population was $23.1 \pm 2.7$ years of age, averaged $1.79 .2 \pm 0.07 \mathrm{~m}$ in height and $75.6 \pm 8.0 \mathrm{Kg}$ in weight, and had a BMI of $23.27 \pm 3.71 \mathrm{Kg} . \mathrm{m}^{-2}$. The volunteers performed exercises $3.36 \pm 1.12$ days/week and achieved a load of $124.54 \pm 22.07 \mathrm{Kg}$ on $1 \mathrm{RM}$ and $74.72 \pm 13.24 \mathrm{Kg}$ on $60 \% 1 \mathrm{RM}$. The center of pressure (CoP) oscillation on the mediolateral plane before and after fatigue induction was $2.89 \pm 0.89 \mathrm{~mm}$ and $4.09 \pm 0.59 \mathrm{~mm}$, respectively, while the corresponding values on the anteroposterior plane were $2.5 \pm 2.2 \mathrm{~mm}$ and $4.09 \pm 2.26 \mathrm{~mm}$, respectively. The CoP oscillation amplitude on the anteroposterior and mediolateral planes exhibited a significant difference before and after fatigue induction ( $\mathrm{p}=0.04$ and $\mathrm{p}=0.05$, respectively). Conclusions: The present study showed that muscle fatigue affects postural control, particularly with the mediolateral and anteroposterior CoP excursion.
\end{abstract}

Keywords: rehabilitation; muscle fatigue; exercise; postural balance.

\section{HOW TO CITE THIS ARTICLE}

Bruniera CAV, Rogério FRPG, Rodacki ALF. Stabilometric response during single-leg stance after lower limb muscle fatigue. Braz J Phys Ther. 2013 Sept-Oct; 17(5):464-469. http://dx.doi.org/10.1590/S1413-35552012005000119

\section{Introduction}

The control of upright posture is achieved through the integration of a complex set of reflex and perceptual processes that ensure the maintenance and recovery of balance. Such processes depend on the uninterrupted flow of afferent impulses that originate in proprioceptive, vestibular, and visual structures. As a consequence, perception deficits may hinder postural control and influence balance ${ }^{1}$. According to some studies, orthopedic injuries ${ }^{2}$, vestibular disorders ${ }^{3}$, and fatiguing exercises ${ }^{4}$ can affect proprioception ${ }^{5,6}$ and therefore also postural control ${ }^{7}$.

Changes in proprioception that occur in response to fatigue ${ }^{8-10}$ may affect neuromuscular control and increase the incidence of injuries ${ }^{11}$. Disorders of the perceptual system can also increase the risk of ligament injury, especially around the knees and ankles ${ }^{5,6,12}$, given the relevant role of these joints in postural control and the maintenance of balance.
The ability of muscle to generate force and power decreases under fatigue conditions ${ }^{13}$, resulting in motor performance deficits ${ }^{14}$ and increasing oscillations during static posture ${ }^{15}$. The effects of fatigue on balance can appear immediately after the performance of exercise and tend to decrease over time ${ }^{16}$. Therefore, balance and the performance of functional tasks decrease following fatiguing exercise $^{17}$.

Balance depends on the ability of the neuromuscular system to react quickly to perturbations that introduce destabilizing forces, the effects of which are minimized by the adjustment of posture ${ }^{18}$. However, a reduction in the ability of the musculoskeletal system to respond quickly to the forces that act on the body and hinder its balance may affect perceptual and effector mechanisms and thus alter the response of the neuromuscular system, resulting in interference with body stability ${ }^{18,19}$. According to certain studies, 
trunk and lower limb muscle fatigue in young adults is associated with a reduction in postural control ${ }^{11,20}$.

Bisson et al. ${ }^{21}$ found no differences between two types of fatiguing protocols involving isometric and isokinetic contractions of the plantar flexor muscles, although both protocols altered the center of pressure (CoP) parameters. In addition, increases in the CoP excursion area, velocity, and variability were found in both the anteroposterior and mediolateral planes. Although the muscles affecting the ankles play a crucial role in the control of the quiet upright posture, the knee extensor muscles are proportionately much more greatly used and are therefore also more exposed to fatigue during the performance of activities of daily living and may exhibit responses different from those observed when fatiguing activities are imposed exclusively on the more distal muscles of the lower body. Therefore, the aim of the present study was to analyze the effect of muscle fatigue induced by resistance training on the knee extensor muscles as well as the stabilometric responses of young individuals in the single-leg stance.

\section{- Method}

A total of 11 young males $(23.1 \pm 2.7$ years old; $1.79 \pm 0.07 \mathrm{~m} ; 75.6 \pm 8.0 \mathrm{Kg}$; and $23.3 \pm 3.71 \mathrm{Kg} . \mathrm{m}^{-2}$ ) participated in the study. The volunteers were acquainted with resistance training, which they performed on a regular basis at least twice per week (number of days/week: $3.36 \pm 1.12$ ) over 3 to 5 months prior to the beginning of the study. The volunteers had no history of lower limb injuries, surgery, or fractures and were not using any medications that could compromise the findings of the study. In addition, individuals with heart or respiratory problems, vestibular or visual dysfunction, or physical impairment, as well as users of medications that interfere with the state of wakefulness and balance (and could therefore interfere with the performance of tests), were excluded. The exclusion criteria were applied following interviews conducted with the volunteers; therefore, their potential unawareness of any of the abovementioned conditions was ruled out. All volunteers agreed to participate in the study and signed an informed consent form approved by the Ethics Committee of the State University of Londrina (Universidade Estadual de Londrina - UEL), Londrina, State of Paraná-PR, Brazil (ruling 94,191, CAAE [Certificado de Apresentação para Apreciação Ética / Certificate of Presentation for Ethical Consideration] 02986012.3.0000.5231).
The volunteers were instructed to not perform moderate or intense physical activity 24 hours before the period of data collection and avoid the ingestion of alcoholic beverages and medications liable to affect balance. The sample included only males because the genders have been shown to differ with regard to the ability to reach and tolerate fatigue ${ }^{22,23}$.

The volunteers attended an initial experimental session, in which anthropometric parameters were measured (body mass and height). Then, they were subjected to a one-repetition maximum (1RM) test ${ }^{24,25}$, following the protocols formulated by the American College of Sports Medicine (ACSM) ${ }^{26}$. This test was used to establish the maximum load that could be moved/lifted in a single full repetition of the knee extension motion performed on a leg flexion-extension machine (Naka-Gym, Fit, Brazil). The maximum load was established by maximum attempts based on a value estimated by the experimenters. The load was gradually increased by $5 \mathrm{Kg}$ per attempt, until the moment when the volunteers were no longer able to perform the full knee extension motion. A 3-minute rest interval was established between attempts. During the entire performance of the test, the volunteers remained in the sitting position, with their knees on the distal end of the machine and their back leaning against the chair. Lateral hand grips were used to stabilize the trunk and avoid accessory motions. Before the 1RM test, the volunteers performed a specific sequence of warming up exercises on the leg extension machine, which included 3 series of 10-12 repetitions without overload separated by 90 -second intervals for recovery.

The second experimental session was scheduled 1 week later. At this time, the volunteers returned to the laboratory and were subjected to a stabilometric test, which was performed before and after the application of a protocol for lower limb exercise designed to induce fatigue. The fatiguing protocol comprised knee extension motions with a load equivalent to $60 \%$ of the 1RM, and the volunteers were instructed to perform the motion with a frequency of $0.133-\mathrm{Hz}$ ( 8 beats per minute $[\mathrm{bpm}]$ ), which was controlled using a metronome (Orange, Digital Korg, USA). The fatiguing protocol was ended when the volunteers became no longer able to maintain the indicated frequency over 2 consecutive or 3 alternate beats or perform the maximum range of the indicated motion.

The stabilometric test was performed with the volunteers standing on the dominant limb for 60 seconds on a force plate (FootWork, AM3, France), which was placed next to the flexion-extension machine to limit the resting time to the bare minimum 
(approximately 5 seconds) between the fatiguing exercise and the stabilometric test. During the test, the volunteers were requested to extend the stance leg and maintain the contralateral hip and knee flexed at $45^{\circ}$ and $90^{\circ}$, respectively. Their upper limbs were allowed to hang along the body, and the trunk was kept upright. The volunteers were instructed to stare fixedly at a dot (with a 0.07-m diameter) placed $1 \mathrm{~m}$ in front of them at eye level. The force plate comprised a rigid base covered by 2.704 capacitive pressure sensors with a size of $7.62 \times 7.62 \mathrm{~mm}$. The equipment included a 16-bit analog-to-digital (A/D) converter, and a sampling frequency of $100 \mathrm{~Hz}$ was used in the tests. The force plate was connected to a microcomputer, and the data were analyzed using the FootWork software (Arkipelago, version 2.9.9.0; the method for data treatment relative to the balance variables was developed together with the AM3 company, in France). A set of stabilometric parameters was established based on the filtered data, and the following variables were measured using the software: CoP oscillation amplitude on the mediolateral and anteroposterior planes; displacement area; and (anteroposterior and mediolateral) root-mean-square velocity.

The Shapiro-Wilk test confirmed the normality of the data, and the repeated-measure t-test was used to establish the effect of the fatiguing protocol on the stabilometric parameters. These tests were performed using the statistical package Statistica 7.0, with $\mathrm{p}<0.05$ as the significance level.

\section{Results}

The load lifted by the volunteers in the $1 \mathrm{RM}$ test was $124.5 \pm 22.1 \mathrm{Kg}$. The $\mathrm{CoP}$ oscillation on the mediolateral plane before and after fatigue induction was $2.89 \pm 0.89 \mathrm{~mm}$ and $4.09 \pm 0.59 \mathrm{~mm}$, respectively, and this difference was significant $(\mathrm{p}=0.04)$. The CoP mean velocity on the mediolateral plane did not change after fatigue induction ( $p>0.05$; before $=6.21 \pm 2.36 \mathrm{~mm} . \mathrm{s}^{-1}$; after $=6.35 \pm 2.26 \mathrm{~mm} . \mathrm{s}^{-1}$ ) and was also not different when measured on the anteroposterior plane $(\mathrm{p}>0.32$; before $=3.9 \pm 0.9$ $\mathrm{mm} . \mathrm{s}^{-1}$; after $\left.=4.64 \pm 1.42 \mathrm{~mm} . \mathrm{s}^{-1}\right)$. In contrast, analysis of CoP oscillation on the anteroposterior plane revealed a significant influence of fatigue $(\mathrm{p}<0.05$; before $=2.5 \pm 2.2 \mathrm{~mm}$; after $=4.09 \pm 2.26 \mathrm{~mm})$. The total $\mathrm{CoP}$ area exhibited an increasing trend following fatigue induction (before $=135.0 \pm 29.62$ $\mathrm{mm}^{2}$; after $=151.72 \pm 16.69 \mathrm{~mm}^{2}$ ), although this increase was not statistically significant $(\mathrm{p}=0.08)$. The CoP root-mean-square speed did not demonstrate changes following application of the fatiguing protocol $\left(\mathrm{p}=0.78\right.$; before $=7.43 \pm 2.22 \mathrm{~mm} \cdot \mathrm{s}^{-1}$; after $\left.=7.96 \pm 2.24 \mathrm{~mm} . \mathrm{s}^{-1}\right)$.

\section{Discussion}

The present study sought to investigate the influence of fatigue of the knee extensor muscles on postural control in healthy individuals, with the hypothesis that fatigue would have acute effects on postural control. These particular muscles were selected because they play an important role in the performance of motions required for both the activities of daily living and the practice of sports $^{27}$. Our results showed that, indeed, fatigue exerted an influence on the somatosensory system and altered certain stabilometric parameters. As the remainder of the components of the control system (visual and vestibular) were not subjected to direct manipulation and were left unaltered, the changes identified in the present study were mostly attributed to the somatosensory system.

Muscle fatigue is defined as the transient inability to generate force or reduction of the production of force needed to perform a given task ${ }^{28}$. The mechanisms underlying the alterations in balance and joint position in localized muscle fatigue have not yet been elucidated but most likely include afferent and efferent components involved in the processes required to maintain functional stability and effective motor control ${ }^{29}$.

The influence of fatigue on balance was found to occur independently from the CoP displacement plane (i.e., anteroposterior or mediolateral). One explanation to account for the decreased ability to maintain body stability may be afforded by the reduction of the muscle capacity to generate fast and precise responses fit to generate the continuous adjustments of the CoP needed to maintain a stable posture. As a consequence, fatigue may have interfered with the muscle capacity to generate the torque required to control the oscillatory motions of the center of body mass ${ }^{30,31}$. Although the maintenance of posture demands a low joint torque, the slower speed of torque generation during the state of fatigue seems to play an important role.

The changes exhibited by the stabilometric parameters after fatigue induction indicated dependence of the sustained postural control on efferent mechanisms during the state of static balance, and similar findings have been reported by other authors, despite the use of different experimental methods. For example, Carter et al. ${ }^{32}$ identified a 
strong influence of the force generating capacity of knee extensors in elderly women (65-75 years old) on their performance in functional tests involving the control of static and dynamic balance. Additionally, Johnston et al. ${ }^{11}$ detected the influence of lower limb fatigue in tests demanding the maintenance of balance during single-leg and double-leg stance. Both sets of findings ${ }^{11,32}$ highlight the effects of fatigue on postural control and also seem to indicate that such changes depend on afferent and efferent mechanisms, a contribution that deserves more thorough attention. Moreover, a previous study involving the induction of fatigue by means of isometric and isokinetic exercises $^{21}$ found a similar reduction in postural control for the CoP variables, which suggests that the reduction of the postural control induced by fatigue is independent from the type of muscle contraction involved. Thus, the poorer performance in postural control following fatigue induction may be associated with proprioceptive deficits capable of impairing the ability to maintain balance and increasing the risk of falls and/or injuries.

The influence of fatigue on postural control was investigated by Yaggie and Armstrong ${ }^{7}$, who observed greater $\mathrm{CoP}$ displacement amplitude in static balance, which lasted until approximately 10 minutes after the end of the fatiguing protocol. This increase in CoP oscillation may also be due to the increased joint rigidity caused by the co-contraction of the agonist/ antagonist pairs ${ }^{33}$ that characterizes muscle fatigue. Together with the loss of their ability to control the $\mathrm{CoP}$, the volunteers utilized a strategy involving the reduction of the displacement velocity. Thus, one may adduce that such strategies were used to improve body control by increasing the rigidity of the system, which oscillated more slowly and over a larger area, as an attempt to reduce the CoP displacement and the unbalance on the anteroposterior and mediolateral planes. The difficulty associated with controlling the motions that increase system rigidity increases together with fatigue, and this may be associated with the greater oscillations exhibited by the $\mathrm{CoP}^{34}$.

A previous study investigated muscle fatigue affecting the ankle, knee, and hip joints as well as the abdominal muscles on the control of dynamic balance ${ }^{35}$, and the results showed that fatigue of the knee and hip joint muscles was associated with less balance reduction compared to other groups of muscles. In addition, Miller and Bird ${ }^{35}$ observed that fatigue of the lower limb proximal muscles exerted a stronger impact on balance as compared to fatigue of the distal muscles. Additionally, the results of the present study revealed a strong effect of fatigue on the ability to maintain static balance. Thus, fatigue of the knee extensor muscles is sufficient to promote significant changes in postural control.

In addition to its effect on the contractile tissues, the literature indicates that fatigue may also influence the afferent system and reduce the sensitivity of a set of peripheral mechanoreceptors located in muscles, ligament, tendon, and capsular structures ${ }^{36}$. Fatigue may also affect the function of such mechanoreceptors, through which late responses are transmitted to the higher brain centers, thus delaying the elaboration of a quick response for controlling oscillations of the body center of mass. Indeed, according to some studies, the proprioceptive function is altered under the state of fatigue, which in turn alters responsiveness by means of efferent impulses towards structures involved in the generation or stabilization of the body segments ${ }^{37}$, thereby interfering with postural control ${ }^{31}$. Therefore, such mechanisms most likely influence postural control, increase the latency of the muscle response, and impair the precision of the continuous adjustment of the $\mathrm{CoP}$, which is required for the postural control system. Furthermore, it should be noted that although protocols investigating postural control using force plates are considered to be one of the most precise methods to identify changes in balance ${ }^{34,38}$, they may not be able to detect discrete differences ${ }^{39}$. The changes observed in the present study cannot be classified as discrete, but rather reflect significant differences relative to the response to muscle fatigue.

\section{Conclusion}

The present study identified a significant effect of fatigue on postural control, namely increased CoP oscillation with regard to stabilometry parameters, which can be understood as an increase in the neuromuscular response to overcome the instability generated by fatigue. Therefore, assessments of postural control should not be attempted following the performance of physical activity or exercise. In addition, the risk of falls and/or injury is most likely greater when the proprioceptive information is reduced and/or altered.

\section{References}

1. Ribeiro F, Oliveira J. Efeito da fadiga muscular local na propriocepção do joelho. Fisioter Mov. 2008;21(2):71-83.

2. Henriksson M, Ledin T, Good L. Postural control after anterior cruciate ligament reconstruction and functional rehabilitation. Am J Sports Med. 2001;29:359-66. PMid:11394609. 
3. Bastos AGD, Lima MAMT, Oliveira LF. Avaliação de pacientes com queixa de tontura e eletronistagmografia normal por meio da estabilometria. Rev Bras Otorrinolaringol. 2005;71(3):305-10. http://dx.doi. org/10.1590/S0034-72992005000300007

4. Yaggie JA, McGregor SJ. Effects of isokinetic ankle fatigue on the maintenance of balance and postural limits. Arch Phys Med Rehabil. 2002;83:224-8. http://dx.doi. org/10.1053/apmr.2002.28032

5. Lattazio PJ, Petrella RJ. Knee proprioception: a review of mechanisms, measurements, and implications of muscular fatigue. Orthopedics. 1998;21:463-70. PMID:9571681.

6. Skinner HB, Wyatt MP, Hodgdon JA, Conard DW, Barrack RL. Effect of fatigue on joint position sense of the knee. J Orthop Res. 1986;4(1):112-8. PMID: 3950803.

7. Yaggie J, Armstrong WJ. Effects of lower extremity fatigue on indices of balance. J Sport Rehabil. 2004;13(4):21-8.

8. Voight ML, Hardin JA, Blackburn TA, Tippett S, Canner GC. The effects of muscle fatigue on and the relationship of arm dominance to shoulder proprioception. J Orthop Sports Phys Ther. 1996;23:348-52. PMid:8727014.

9. Carpenter JE, Blasier RB, Pellizon GG. The effects of muscle fatigue on shoulder joint position sense. Am J Sports Med.1998;26:262-5. PMid:9548121.

10. Forestier N, Teasdale N, Nougier V. Alteration of the position sense at the ankle induced by muscular fatigue in humans. Med Sci Sports Exerc. 2002;34(1):117-22. PMid:11782656. http://dx.doi. org/10.1097/00005768-200201000-00018

11. Johnston RB, Howard ME, Cawley PW, Losse GM. Effect of lower extremity muscular fatigue on motor control performance. Med Sci Sports Exerc. 1998;30:1703-7. http://dx.doi.org/10.1097/00005768-199812000-00008

12. Lephart SM, Fu FH. Proprioception and neuromuscular control in joint stability. Champaign: Human Kinetics; 2000. PMCid:PMC1323397.

13. Enoka RM, Stuart DG. Neurobiology of muscle fatigue. J Appl Physiol. 1992;72:1631-48. PMid:1601767.

14. Van Daele U, Huyvaert S, Hagman F, Duquet W, Van Gheluwe B, et al. Reproducibility of postural control measurement during unstable sitting in low back pain patients. BMC Musculoskelet Disord. 2007;8:44-52. PMid:17519016 PMCid:PMC1888688. http://dx.doi. org/10.1186/1471-2474-8-44

15. Gribble PA, Hertel J. Effect of lower-extremity muscle fatigue on postural control. Arch Phys Med Rehabil. 2004;85:589-92. http://dx.doi.org/10.1016/j. apmr.2003.06.031

16. Witvrouw E, Danneels L, Asselman P, D'have T, Bier D. Muscle flexibility as a risk factor for developing muscle injuries in male professional soccer players. A prospective study. Am J Sports Med. 2003;3(1):41-6.

17. Noakes TD. Physiological models to understand exercise fatigue and the adaptations that predict or enhance athletic performance. Scand J Med Sci Sports. 2000;10:123-45. PMid:10843507. http://dx.doi. org/10.1034/j.1600-0838.2000.010003123.x

18. Harkins KM, Mattacola CG, Uhl TL, Malone TR, McCrory JL. Effects of two ankle fatigue models on the duration of postural stability dysfunction. J Athl Train. 2005;40(3):191-4. PMCID: PMC1250260.

19. Gribble P, Hertel J. Effect of hip and ankle muscle fatigue on unipedal postural control. J Electromyogr Kinesiol. 2004;14:641-6. PMid:15491838. http://dx.doi. org/10.1016/j.jelekin.2004.05.001

20. Cetin N, Bayramoglu M, Aytar A, Surenkok O, Yemisci OU. Effects of Lower-Extremity and Trunk Muscle Fatigue on Balance. Open Sports Med J. 2008;2:16-22. http://dx.doi.org/10.2174/1874387000802010016

21. Bisson EJ, Remaud A, Boyas S, Lajoie Y, Bilodeau M. Effects of fatiguing isometric and isokinetic ankle exercises on postural control while standing on firm and compliant surfaces. J Neuroeng Rehabil. 2012;9:39. PMid:22698065 PMCid:PMC3502289. http://dx.doi. org/10.1186/1743-0003-9-39

22. Doyle JW, Towse TF. Human skeletal muscle responses vary with age and gender during fatigue due to incremental isometric exercise. J Appl Physiol. 2002;93:1813-23. PMid:12381770.

23. Russ DW, Kent-Braun JA. Sex differences in human skeletal muscle fatigue are eliminated under ischemic conditions. J Appl Physiol. 2003;94:2414-22. PMid:12562681.

24. Hoeger WWK, Hopkins DR, Barette SL, Hale DF. Relationship between repetitions and selected percentages of one repetition maximum: a comparison between untrained and trained males and females. J Appl Sport Sci Res. 1990;4:47-54.

25. Marchetti PH, Uchida MC. Influência da fadiga unilateral de membro inferior sobre o salto vertical bilateral. Rev Bras Med Esporte. 2011;17(6):405-8. http://dx.doi. org/10.1590/S1517-86922011000600007

26. American College of Sports Medicine. Position stand: progression models in resistance training for healthy adults. Med Sci Sports Exerc. 2009;41(3):687-708. PMid:19204579.

27. Weber FS, Siva BGC, Cadore EL, Pinto SS, Pinto RS. Avaliação isocinética da fadiga em jogadores de futebol profissional. Rev Bras Ciênc Esporte. 2012;34(3):775-88 http://dx.doi.org/10.1590/S0101-32892012000300017

28. Bigland-Ritchie B, McKenzie DK, Gorman RB, Gandevia SC. Central and peripheral fatigue of human diaphragm and limb muscles assessed by twitch interpolation. J Physiol. 1992;454:643-56. PMid:1335508 PMCid:PMC1175625.

29. Bryan LRI, Scott ML. The Sensorimotor System, Part I: The Physiologic Basis of Functional Joint Stability. J Athl Train. 2002;37(1):71-9. PMCID: PMC164311.

30. Lee S, Becker C, Binder-Macleod S. Activation of human quadriceps femoris muscle during dynamic contractions: effects of load on fatigue. J Appl Physiol. 2000;89(3):92636. PMid: 10956335.

31. Gefen A, Megido-Ravid M, Itzchak Y, Arcan M. Analysis of muscular fatigue and foot stability during highheeled gait. Gait Posture. 2002;15:56-63. http://dx.doi. org/10.1016/S0966-6362(01)00180-1

32. Carter ND, Khan KM, Mallinson A. Knee extension strength is a significant determinant of static and 
dynamic balance as well as quality of life in older community-dwelling women with osteoporosis. Gerontology. 2002;48:360-8. PMid:12393951. http:// dx.doi.org/10.1159/000065504

33. Potvin JR, O'Brien PR. Trunk muscle co-contraction increases during fatiguing, isometric, lateral bend exertions. Possible implications for spine stability. Spine (Phila Pa 1976). 2002;23(7):774-/80.

34. Duarte M, Freitas SMSF. Revision of posturography based on force plate for balance evaluation. Rev Bras Fisioter. 2010;14(3):183-92. http://dx.doi.org/10.1590/ S1413-35552010000300003

35. Miller PK, Bird AM. Localized muscle fatigue and dynamic balance. Percept mot skills. 1976;42:135-8. http://dx.doi.org/10.2466/pms.1976.42.1.135

36. Grigg P. Peripheral neural mechanism in proprioception. J Sport Rehabil. 1994;3:2-17.
37. Chabran E, Maton B, Fourment A. Effects of postural muscle fatigue on the relation between segmental posture and movement. J Electromyogr Kinesiol. 2002;12:67-79. http://dx.doi.org/10.1016/S1050-6411(01)00027-X

38. Shumway-Cook A, Woollacott M. Controle Motor: Teoria e aplicações práticas. 2a . ed. Barueri: Manole; 2003.

39. Melzer I, Kurz I, Oddsson LA. Retrospective analysis of balance control parameters in elderly fallers and nonfallers. Clin Biomech. 2010;25:984-8. PMid:20696509. http://dx.doi.org/10.1016/j.clinbiomech.2010.07.007

\section{Correspondence}

Carlos Alberto Veiga Bruniera

Rua João Wyclif, 255, apt. 1503

CEP 86050-450, Londrina, PR, Brasil

e-mail: cavbruniera@gmail.com 